University of Nebraska - Lincoln

DigitalCommons@University of Nebraska - Lincoln

Library Philosophy and Practice (e-journal)

Libraries at University of Nebraska-Lincoln

July 2017

Knowledge and Use of Electronic Information Resources by Medical Students at Al-Jouf University in Saudi Arabia

Aquil Ahmed

Al-Jouf University, aahmed2006@gmail.com

Sulaiman Al-Reyaee Dr

Al-Imam Mohammed Ibn Saud Islamic University, reyaee@gmail.com

Follow this and additional works at: http://digitalcommons.unl.edu/libphilprac

Part of the Library and Information Science Commons

Ahmed, Aquil and Al-Reyaee, Sulaiman Dr, "Knowledge and Use of Electronic Information Resources by Medical Students at Al-Jouf University in Saudi Arabia" (2017). Library Philosophy and Practice (e-journal). 1524.

http://digitalcommons.unl.edu/libphilprac/1524 


\title{
Knowledge and Use of Electronic Information Resources by Medical Students at Al-Jouf University in Saudi Arabia
}

\author{
Aquil Ahmed \\ Medical Librarian, \\ College of Medicine, \\ Al-Jouf University, \\ Al-Jouf, Saudi Arabia \\ Email: $\underline{\text { ahhmed2006@gmail.com }}$
}

\section{Dr. Sulaiman Al-Reyaee}

Professor,

Department of Information Studies,

Faculty of Computer and Information Science, Al-Imam Mohammed Ibn Saud Islamic University

Riyadh, Saudi Arabia

Email: reyaee@gmail.com 


\title{
Knowledge and Use of Electronic Information Resources by Medical Students at Al-Jouf University in Saudi Arabia
}

\begin{abstract}
Electronic resources are becoming an integral part of the modern education system, especially in higher education settings. Due to the need of medical professionals for high quality, authoritative, relevant, accurate and timely information, students studying in healthcare institutions need to know the various e-resources and the best suitable way to track and access them in order to support their learning and evidence-based medical practice. The present study has tried to assess and compare the awareness and usability level of medical students of two different colleges at Al-Jouf University in using the subscribed electronic resources. The main purpose was to determine students' knowledge and use of e-databases, and to identify the areas in which further training and research needed. $A$ questionnaire, supplemented by an unstructured interview was used to collect data from 300 randomly selected undergraduate medical students. The study found that the awareness and utilization level of students related to available e-databases varied significantly especially when comparing individual colleges and databases. The overall knowledge and use of e-databases by medical students was much higher than the dental students and those who were aware of the existence of e-resources found using e-books' databases more than those containing journal publications and EBM. The overall low response from dental students and lack of e-resources useful to them, are very much evident from the study. The study also found that those dissatisfied with the subscribed e-resources tend to use general search engines and databases of other university in order to meet their information needs. The paper concludes that the medical students lack the necessary information literacy skills needed to meet their academic and research requirements. It is recommended that the medical librarians and faculty should come together and intensify their efforts through proper information literacy programs in order to educate students how to use these resources effectively.
\end{abstract}

\section{Keywords:}

Electronic Databases, Academic Libraries, Medical Students, Information Seeking Behavior, Al-Jouf University, Saudi Arabia 


\section{INTRODUCTION}

Students in Medical Sciences today need current and evidence-based information applicable to their problem-based learning (PBL) and clinical problems. Effective information searching and access to the most nascent and relevant information are critical for healthcare professionals. These problems were tried to be solved by implementing the latest technologies on sources and services of medical libraries. Electronic databases, as one of the significant scientific information resources, have provided access to the qualitative and quantitative information more precisely and more quickly (Nemati Anaraki and Babalhavaeji 2013).

E-Databases containing journal articles, e-books, reference sources and conference papers, among others, have become an established component of many academic libraries' collection. Access to resources is now considered more important than mere collection building. These e-resources are convenient to use, available at an affordable cost and can be accessed from anywhere and by many users simultaneously (Baro, Endouware, and Ubogu 2011). Academic libraries in all countries spend huge amounts of money on these resources to satisfy the teaching, learning and research needs of its clientele. It is therefore imperative from the part of the university to ensure that these databases are optimally utilized to contribute to the academic excellence and achievement of its user community.

However, in spite of the value and importance of e-databases, it is widely held view that these resources are not fully utilized. Reasons for this inability to effectively exploit these resources are generally attributed to lack of competence (Gruppen 1990, Zondi 1992), awareness (Adams and Bonk 1995, Majid and Mansor 1996, Roberts 1995), and adequate ICT infrastructure (Dukić 2013, Zabed Ahmed 2013), among others. The manifestation of these reasons may differ from place to place or from situation to situation. The failure of health professionals in making effective use of electronic resources has been a cause of concern to librarians worldwide. It is against this background that we have attempted to investigate the awareness and use of available e-resources by the students of Faculty of Medical Sciences in Al-Jouf University.

\section{LITERATURE REVIEW}


In order to find and use the current best information in any discipline, the literature must be searched, selected and appraised. The literature search in this study indicates that many studies have so far been done on electronic databases with regard to awareness, usage, access, relevance, orientations and training, preference and evaluation among others. It is observed that sometimes there is a gap between awareness and usage of electronic resources. Users are either aware of the resources and use them, or aware, but do not use them, or sometimes they are unaware and therefore do not use them. Studies, such as Atakan et al. (2008), Chirra and Madhusudhan (2009), Dee and Stanley (2005), Eskola (2005), Haines (2010) all found that users were aware of the digital information resources and used them. For example, Haines (2010) in a survey on the use of electronic resources by undergraduate and post-graduate students of basic sciences at the University of Vermont, United States, revealed that all the respondents $(100 \%)$ were aware of the digital information resources of the university and accessed them. However, studies like Dadzie (2005), Ercegovac (2009), Manda (2005), Okello-Obura (2010) reported that users were not aware of most of the resources available to them by their respective institutions and therefore affected their usage. Manda (2005) for example, revealed that electronic resources available through the Program for the Enhancement of Research Information (PERI) at the research institutions in Tanzania were underutilized as the potential users were not aware due to lack of publicity.

Nemati Anaraki and Babalhavaeji (2013) in their survey result of three Iranian universities pinpointed that when students were not aware of the availability of e-resources in their institutions, they tend to use general search engines in order to fulfill their information needs. The respondents admitted that their lack of awareness about the resources was their most significant problem as only $16 \%$ of them reported to be well acquainted with the available resources. In a survey conducted in two specialized public universities in Bangladesh, Zabed Ahmed (2013) also found that the respondents were using free electronic resources more than the university's subscribed resources due to lack of awareness.

Some research studies such as Asemi and Riyahiniya (2007), Baro, Endouware, and Ubogu (2011) argued that it is not always the case that awareness may lead to usage of a database. It could happen that respondents' awareness level may be higher than usage. They reported that awareness level of their respondents was much more than usage. For example, Baro, Endouware, and Ubogu (2011) pointed out that while $23.2 \%$ users reported to be aware of the Medline database, only $17 \%$ found actually using it. Similarly, while $60.8 \%$ were aware of HINARI, only $38.8 \%$ used it. Swain (2010) highlighted that awareness could be influenced by the interest and exposure that a user has 
in the database. In his study of students' keenness on the use of e-resources in the business schools of Orissa (India), he found that over $62.5 \%$ and $52.6 \%$ users were aware of EBSCO and Emerald respectively while below the $40 \%$ reported to be aware of other databases.

Various research studies have been carried out focusing on the factors influencing the optimal usage of e-databases. Familiarity, convenience, exposure, infrastructure, relevance, search skills and training have been cited as major influencing factors. In a study on how graduate students perceive, use and manage digital information resources at the National University of Taiwan, Wu and Chen (2012) found that the pattern of usage varied according to the subject background of the respondents. He concluded that humanities students found the e-resources less important than the students of other disciplines. Talja and Maula (2003) and Atakan et al. (2008) made the similar assertions that disciplinary differences can actually influence the usage of databases. Hong Sinh and Thi Hong Nhung (2012) argued that users' behavior like, purpose of usage, preferred types of materials, search techniques, ways to learn the search, and expectations and difficulties in using the e-resource can also influence the usage. In their survey at Central Vietnam National University, they found that $87.5 \%$ users requested for full-text articles as compared to $12.5 \%$ who requested for abstracts. Examining the usage statistics of the library, Coombs (2005) discovered similar findings that users were found accessing particular types of resources. Okello-Obura (2010) and Ndinoshiho (2010) pointed out that students tend to use familiar databases more than others. For example, in his study of nursing students in the University of Namibia, Ndinoshiho (2010) revealed that $86.4 \%$ users did not use the available databases because they were unfamiliar to them. Some studies, like Cothran (2011), He et al. (2012) argued that students prefer to use convenient and user friendly databases more than others. In his study of graduate students, Cothran (2011) claimed that academic search engines such as Google scholar and CiteSeers were used more as compared to subscribed databases because the users found them easy to learn, navigate and use. According to Nisha and Ali (2012), relevancy, currency and rich content also influence the use of a particular database.

With regard to the satisfaction derived from the usage of e-resources, Zabed Ahmed (2013) in his study found that respondents were not satisfied with the subscribed e-resources because of the poor IT infrastructure, slow download speed, difficulty in finding relevant information and inability to access from home. Mbabu, Bertram, and Varnum (2013) in their study at the University of Michigan also arrived at similar findings. Kai-Wah Chu and Law (2005) presumed that knowledge, search expertise and usage of databases by students increase as they progress in their studies. They argued 
that with the help of instruction, training and usage, the familiarity of students with different databases developed. Dudley (2013) and Nemati Anaraki and Babalhavaeji (2013) in their study suggested for faculty-librarian collaborative efforts in organizing orientation and training programs at regular intervals in order to make the users aware and thereby enhance the usage of electronic databases.

\section{NATURE OF THE PROBLEM}

The Medical Sciences Library (MSL) of Al-Jouf University, Al-Jouf, Saudi Arabia, has made significant investments in e-resources and accompanying computer-based technology to ensure their access to its clientele. However, the resources appeared to be underutilized by the students of medical sciences. The level of usage of e-databases by students and the usefulness of such facilities are not known because there has not been any major study to that effect. This study is intended to investigate students' awareness and use of electronic resources provided by the MSL and the areas of training needed by students to utilize the available e-resources effectively and efficiently. In addition, it is intended to recommend how the library could achieve the identified needs and what strategies the library could take to improve service as well as what areas the library could research further? With limited availability of published literature in the field pertaining to usage of eresources by the students of Saudi universities, the present study hopes to add to the body of literature about the use of electronic resources in Saudi Arabia and encourages further studies of this nature for different user groups.

\section{BACKGROUND}

\section{Faculty of Medical Sciences at Al-Jouf University}

Faculty of Medical Sciences (FMS) at Al-Jouf University was established in 2006 (1427 H) with the aim of enhancing the health of people in Aljouf Region by training and graduating healthcare professionals in a broad range of diagnostic, communication and organizational skills who are committed to lifelong learning and research; provide high quality patient care, and serve the people of Saudi Arabia in general and the region in particular. It has 3 colleges located in the city of SakakaCollege of Medicine and College of Dentistry are located in a single campus, whereas College of Pharmacy is located in a separate campus. The total undergraduate student population of both these colleges (College of Medicine \& College of Dentistry) has over 500. The educational methodology is Problem-based Learning (PBL). The first three years are devoted to study basic health sciences and the next two years are considered clinical years. All the three colleges of Medical 
Sciences are equipped with high quality laboratories and equipments and the study curriculum distributed among clinical and basic science departments, committed to teaching both the science and the medicine.

\section{Medical Sciences Library}

The Medical Sciences Library (MSL) is a part of the campus library system of Al-Jouf University and facilitates access to both traditional print formats and electronic information resources. The library is situated in the building of College of Medicine and ensures its services to all medical fraternity of the University. It currently holds more than 5,000 volumes of printed books, subscribes to thousands of electronic journals and e-book titles and provides access to many other electronic resources. Besides providing usual library services and separate reading areas for both male and female students and faculties, the library facilitates a training room equipped with 20 computer terminals, a slide projector and video conferencing facility in order to conduct information literacy training programs.

The e-databases available in the Al-Jouf University Library System consist of subscriptions based on consortia, university's direct subscription and open access. With the initiatives of Saudi Ministry of Higher Education, a consortium - Saudi Digital Library (SDL) was established in November 2010 with the aim of purchasing and facilitating electronic database access to all public and private Saudi universities in order to reduce the unit cost of these resources. Since its inception, SDL has been striving to provide access to a wide range of e-resources to all universities and research institutions across the country. This situation is even helpful to a large number of Distance Learners in Saudi Universities as they can access the resources from anywhere.

The number of subscribed medical databases at the moment amounts to about 46 . They cover most subject areas in the medicine, dentistry and pharmacy. These contain full text electronic journal articles, bibliographic information, abstracts, e-books, among others. The databases are renewed annually by subscription. Infrastructure wise, the university provides modest ICT facilities for its constituents to enable them access e-resources for teaching, learning and research. To ensure better access and use, at the beginning of every academic year, newly admitted students and faculty undergo library orientation and library tour programs in order to be aware of the available resources and services. 


\section{METHODOLOGY}

The present study was conducted in the Medicine and Dental Colleges of Al-Jouf University, Skaka, (Saudi Arabia) in order to assess the trend of e-database usage among undergraduate students. The total student population of these two colleges for the year 2015-2016 session as per university enrollment statistics, stood at over 500. A total of 300 medical students (150 each from Medicine and Dental Colleges) was selected using random sampling techniques. However, a proportional sampling unit was selected from each class to ensure unbiased representation. This constituted $60 \%$ of the entire population. A questionnaire titled 'Awareness and Use of Electronic Information Resources' was prepared in English containing 12 items pertaining to existing trends and knowledge regarding e-database awareness and usage. The questionnaire was structured to ensure that all pertinent variables were measured. In order to maximize the percentage of respondents' participation, the questionnaires were administered during class time with the permission of the faculty. In addition, to supplement the data from the questionnaire, the researchers engaged 12 students (6 from each college) randomly for an unstructured interview in which the students' responses were recorded. The descriptive statistics were analyzed using frequency counts and percentages.

\section{STUDY LIMITATION}

This study was confined to undergraduate male students of College of Medicine and College of Dentistry, affiliated with the FMS of Al-Jouf University. The study was also restricted to use analysis of electronic information resources.

\section{RESULTS AND DISCUSSIONS}

\section{Demographics of the Respondents}

Out of the three hundred students administered with questionnaires, 154 respondents returned their duly completed questionnaires. This represented a compliance rate of $51.3 \%$. Of the total respondents, $111(74 \%)$ were from the College of Medicine while $43(28.7 \%)$ were from college of Dentistry (Table 1). The data analysis clearly states that the students of medicine college responded enthusiastically than their counterpart.

Table 1: Population Distribution of the Students Studied

\begin{tabular}{|c|c|c|c|}
\hline College & $\begin{array}{c}\text { Total Sample } \\
\text { Population }\end{array}$ & Response & Percentage \\
\hline
\end{tabular}




\begin{tabular}{|r|c|c|c|}
\hline College of Medicine & 150 & 111 & 74 \\
\hline College of Dentistry & 150 & 43 & 28.7 \\
\hline Total & $\mathbf{3 0 0}$ & $\mathbf{1 5 4}$ & $\mathbf{5 1 . 3}$ \\
\hline
\end{tabular}

Source: Field data, 2016

In addition, the distribution among the various classes was $52(33.8 \%)$ students from the $1^{\text {st }}$ year, followed by $42(27.3 \%)$ from the $2^{\text {nd }}$ year, $26(16.9 \%)$ in $3^{\text {rd }}$ year, $21(13.6 \%)$ in $4^{\text {th }}$ and $13(08.4 \%)$ in $5^{\text {th }}$ year respectively. This meant that the students of $1^{\text {st }}$ and $2^{\text {nd }}$ year were more aware and responded better than the older students. It is important to note that though the number of student representatives from each year of study was proportional, the responses of older students from both colleges were poorer than the new undergraduate students (Table 2). This clearly indicates that the new students got benefited with the library orientation \& training programs organized periodically.

Table 2: Study year-wise Distribution of Respondents

\begin{tabular}{|c|c|c|c|c|}
\hline Students' Study Year & $\begin{array}{l}\text { Medicine College } \\
\text { Respondents }\end{array}$ & $\begin{array}{l}\text { Dental College } \\
\text { Respondents }\end{array}$ & $\begin{array}{c}\text { Total } \\
\text { Respondents }\end{array}$ & $\%$ \\
\hline $1^{\text {st }}$ year & 38 & 14 & 52 & 33.8 \\
\hline $2^{\text {nd }}$ year & 30 & 12 & 42 & 27.3 \\
\hline $3^{\text {rd }}$ year & 17 & 09 & 26 & 16.9 \\
\hline $4^{\text {th }}$ year & 15 & 06 & 21 & 13.6 \\
\hline $5^{\text {th }}$ year & 11 & 02 & 13 & 08.4 \\
\hline Total & 111 & 43 & 154 & 100 \\
\hline
\end{tabular}

Source: Field data, 2016

\section{Knowledge of Electronic Resources}

To assess the awareness level of respondents about the databases, they were asked whether they have ever heard of e-databases available to their institution. The results, as shown in Table 3 revealed that the majority of them have heard about the databases. Of the total respondents, $n=140$ (90.9\%) responded in affirmative, while $n=14$ (9.1\%) replied in negative. Of those $(90.9 \%)$ who responded in affirmation, roughly $n=106(75.7 \%)$ were from College of Medicine, while $n=34(24.3 \%)$ were from College of Dentistry. The finding that $90.9 \%$ of respondents had heard of the databases before, concurred with the findings by Chirra and Madhusudhan (2009), Kwafoa, Osman, and AffulArthur (2014), Nisha and Ali (2012) that recorded over 90\% awareness of the databases in their institutions. This also indicates that the students got benefited with the library information literacy programs organized periodically to make them aware of the available resources.

Although, the majority of respondents indicated that they were very much aware of the E-databases' availability, yet they varied unexpectedly when they were asked to mention the databases they know about. The most mentioned databases by above $10 \%$ (on average) of respondents were 
AccessMedicine (87\%), ClinicalKey (84.4\%), Science Direct (74.7\%) and McGraw-Hill (57.1\%). The finding was not surprising since most of the students by virtue of their courses might have had more knowledge of databases related to E-books. It is, therefore, evident from the findings that students were more aware of the databases containing e-books than those related to journal publications and Evidence-based Medicine (EBM). This also shows their lack of involvement in research work. They are more concerned to their courses of study than the research work. In addition, the result indicated that most of the students from both colleges have named the similar e-book databases.

Table 3: Awareness Level of Respondents about the Databases

\begin{tabular}{|c|c|c|c|c|c|c|}
\hline \multirow{3}{*}{\begin{tabular}{|l|} 
Awareness \& Knowledge \\
Have you ever heard about E-Databases? \\
\end{tabular}} & \multicolumn{4}{|c|}{ Colleges } & \multirow{2}{*}{\multicolumn{2}{|c|}{ Total }} \\
\hline & \multicolumn{2}{|c|}{ Medicine } & \multicolumn{2}{|c|}{ Dentistry } & & \\
\hline & Freq & $\%$ & Freq & $\%$ & Freq & $\%$ \\
\hline Yes & 106 & 75.7 & 34 & 24.3 & 140 & 90.9 \\
\hline No & 05 & 35.7 & 09 & 64.3 & 14 & 9.1 \\
\hline \multicolumn{7}{|c|}{ Kindly name the database that you know about? (Open ended questions, Check all that apply) } \\
\hline Embase & 00 & 00.0 & 00 & 00.0 & 00 & 00.0 \\
\hline PubMed & 41 & 36.9 & 23 & 53.5 & 64 & 41.5 \\
\hline MedScape & 03 & 02.7 & 00 & 00.0 & 03 & 01.9 \\
\hline Medline Plus & 38 & 34.2 & 16 & 37.2 & 54 & 35.0 \\
\hline The Cochrane library & 00 & 00.0 & 00 & 00.0 & 00 & 00.0 \\
\hline Ovid & 28 & 25.2 & 08 & 18.6 & 36 & 23.3 \\
\hline CINAHL Plus & 00 & 00.0 & 00 & 00.0 & 00 & 00.0 \\
\hline SCOPUS & 03 & 02.7 & 00 & 00.0 & 03 & 01.9 \\
\hline ClinicalKey & 108 & 97.3 & 22 & 51.2 & 130 & 84.4 \\
\hline Science Direct & 87 & 78.4 & 28 & 65.1 & 115 & 74.7 \\
\hline Uptodate & 11 & 09.9 & 00 & 00.0 & 11 & 07.1 \\
\hline BMJ & 09 & 08.1 & 01 & 02.3 & 10 & 06.4 \\
\hline AccesMedicine & 106 & 95.4 & 28 & 65.1 & 134 & 87.0 \\
\hline DynaMed & 02 & 01.8 & 00 & 00.0 & 02 & 01.3 \\
\hline Wiley & 24 & 21.6 & 11 & 25.6 & 35 & 22.7 \\
\hline Springer & 17 & 15.3 & 09 & 20.9 & 26 & 16.9 \\
\hline Web of Science & 02 & 01.8 & 00 & 00.0 & 02 & 01.3 \\
\hline ProQuest & 48 & 43.2 & 18 & 41.9 & 66 & 42.8 \\
\hline EBSCO & 45 & 40.5 & 14 & 32.6 & 59 & 38.3 \\
\hline McGraw-Hill & 65 & 58.5 & 23 & 53.5 & 88 & 57.1 \\
\hline Anatomy.Tv & 58 & 52.2 & 11 & 25.6 & 69 & 44.8 \\
\hline Others & 13 & 11.7 & 29 & 67.4 & 51 & 27.3 \\
\hline
\end{tabular}

\section{Sources of Information about the Databases}

Mbabu, Bertram, and Varnum (2013) rightly said that students learn about library online resources through a variety of sources, such as, through lecturers and teaching staff, librarians, library orientation classes, friends and even looking it up by themselves. Data analysis of the survey revealed that the majority of students indicated library staff $120(77.2 \%)$ as their primary source of awareness and knowledge about the availability of e-resources (Table 4). This was followed by 
lecturers 84 (54.5\%), library website $69(44.8 \%)$ and college students \& friends 60 (39\%). This finding is similar to those of Kwadzo (2015) and Chirra and Madhusudhan (2009) where the majority of students (over 60\%) mentioned library staff and lecturers as sources of information about the eresources they new about.

Table 4: Sources of Information about the Databases

\begin{tabular}{|l|c|c|c|c|c|c|}
\hline \multirow{2}{*}{ Sources of Awareness \& Knowledge } & \multicolumn{4}{|c|}{ Colleges } & \multicolumn{2}{c|}{ Total } \\
\cline { 2 - 7 } & \multicolumn{2}{|c|}{ Medicine } & \multicolumn{2}{|c|}{ Dentistry } & \multicolumn{2}{c|}{} \\
\cline { 2 - 7 } & Freq & \% & Freq & \% & Freq & $\%$ \\
\hline Library website & 41 & 36.9 & 28 & 65.1 & 69 & 44.8 \\
\hline College website & 00 & 00.0 & 00 & 00.0 & 00 & 00.0 \\
\hline Library Staff & 89 & 80.2 & 31 & 72.0 & 120 & 77.2 \\
\hline Lecturer & 56 & 50.4 & 28 & 65.1 & 84 & 54.5 \\
\hline College Students \& Friends & 36 & 32.4 & 22 & 51.2 & 60 & 39.0 \\
\hline Search Engine & 28 & 25.2 & 11 & 25.6 & 39 & 25.3 \\
\hline
\end{tabular}

In the case of individual colleges, the number of respondents varied even though in both cases the majority mentioned library staff and lecturers as their prime source of information about the consortium of e-resources. This finding is significant because it is in order that lecturers and library staff who have greater influence over the students should spearhead the awareness creation and recommendation of the use of databases. This also indicates the faculty-librarian collaboration which is of course a good sign for promoting the awareness $\&$ use of available resources in the future. It is advisable that lecturers should include relevant databases in the reading lists they provide the students apart from just informing them by word of mouth.

However, the negative percentage of the College website $(0 \%)$ as per survey results, should be of concern. This could be an indication that college website is almost obsolete and not updated at regular intervals. Students seldom visit on it for any information they require. Today, the institution's website is considered vital in providing and promoting services to students. It is recommended to make the website interactive and update it regularly with new information in order to promote services to patrons.

\section{Students' Usage of E-Resources}

Data analysis revealed that about (72.7\%) students reported having used some of the databases before. This result is similar to those of Kwafoa, Osman, and Afful-Arthur (2014) and other studies in which percentage of usage is usually reported lower than awareness. This also shows that more efforts are required to get all the students use these important resources. The inability to use 
electronic resources effectively in the present study could be as a result of lack of necessary skills to use them coupled with lack of awareness. The Association of American Medical Colleges (AAMC) rightly states that "to practice medicine in the $21^{\text {st }}$ century, medical students must be given a strong grounding in the use of computer technology to manage information, support patient care decisions, select treatments, and develop their abilities as lifelong learners"(Moberg and Whitcomb 1999).

The findings of the study show that despite this high response of usage, accessing an individual database did not match to the overall usage and varied significantly. The most used database on an average was Clinicalkey 104 (67.5\%), followed by AccessMedicine 101 (65.6\%), Science Direct 62 (40.2\%), McGraw-Hill 45 (29.2\%) and Pubmed 34 (22\%). The result was not as expected as the most known database was AccessMedicine whereas the most used databases is Clinicalkey (Table 5). This is probably due to the reason that both these databases provide e-books, but Clinicalkey is more comprehensive and provides download facility as well whereas AccessMedicine is not so comprehensive and facilitates only online reading.

Table 5: Distribution of Usage of E-Databases

\begin{tabular}{|l|c|c|c|c|c|c|}
\hline \multirow{2}{*}{ Databases } & \multicolumn{4}{|c|}{ Colleges } & \multicolumn{2}{c|}{ Total } \\
\cline { 2 - 7 } & \multicolumn{2}{|c|}{ Medicine } & \multicolumn{2}{c|}{ Dentistry } & \multicolumn{2}{c|}{} \\
\cline { 2 - 6 } & Freq & $\%$ & Freq & $\%$ & Freq & $\%$ \\
\hline Embase & 00 & 00.0 & 00 & 00.0 & 00 & 00.0 \\
\hline PubMed & 23 & 22.7 & 11 & 25.6 & 34 & 22.0 \\
\hline MedScape & 00 & 00.0 & 00 & 00.0 & 00 & 00.0 \\
\hline Medline Plus & 17 & 15.3 & 12 & 27.9 & 29 & 18.8 \\
\hline Ovid & 18 & 16.2 & 06 & 13.9 & 24 & 15.6 \\
\hline SCOPUS & 00 & 00.0 & 00 & 00.0 & 00 & 00.0 \\
\hline ClinicalKey & 88 & 79.3 & 16 & 37.2 & 104 & 67.5 \\
\hline Science Direct & 43 & 38.7 & 19 & 44.2 & 62 & 40.2 \\
\hline Uptodate & 00 & 00.0 & 00 & 00.0 & 00 & 00.0 \\
\hline BMJ & 02 & 01.8 & 00 & 00.0 & 02 & 01.3 \\
\hline AccesMedicine & 93 & 83.8 & 08 & 18.6 & 101 & 65.6 \\
\hline DynaMed & 00 & 00.0 & 00 & 00.0 & 00 & 00.0 \\
\hline Wiley & 16 & 14.4 & 04 & 09.3 & 20 & 13.0 \\
\hline Springer & 05 & 04.5 & 00 & 00.0 & 05 & 03.2 \\
\hline Web of Science & 00 & 00.0 & 00 & 00.0 & 00 & 00.0 \\
\hline ProQuest & 21 & 18.9 & 10 & 23.2 & 31 & 20.1 \\
\hline EBSCO & 16 & 14.4 & 02 & 04.6 & 18 & 11.7 \\
\hline McGraw-Hill & 32 & 28.8 & 13 & 30.2 & 45 & 29.2 \\
\hline Anatomy.Tv & 13 & 11.7 & 00 & 00.0 & 13 & 08.4 \\
\hline Others & 08 & 07.2 & 26 & 60.5 & 39 & 22.0 \\
\hline
\end{tabular}

The data vary significantly in the case of individual colleges as well. The overall use of databases by medical students is higher than the dental students. It is clear from the data analysis that the medical students are more aware and use the e-resources better than the Dental students. In the case of individual database also, a very low percentage of Dental students(18.6\%) as compared to 
Medical students (83.8\%) reported having used AccessMedicinebecause of the nature and content of the database which is more useful to medical professionals than their counterpart. Similarly, a considerable number of dental students $(72.1 \%)$ indicated to use databases other than those subscribed by the University. Some of the students made it clear to access Qassim University database of e-books. In addition, it is evident from the data analysis that the students are using Ebook databases more than the databases containing journal articles. It shows the lack of research involvement and activity from the part of the students.

In addition, the data analysis also found some differences when comparing the percentages of awareness and usage of the databases. For example, $35 \%$ indicated they were aware of Medline Plus but only $18.8 \%$ indicated using it. The trend was the same for PubMed, Ebscohost, ProQuest, McGraw-Hill and Anatomy.Tv. This finding, to some extent corresponds with the findings of Asemi and Riyahiniya (2007), Baro, Endouware, and Ubogu (2011), Ndinoshiho (2010) and Kwafoa, Osman, and Afful-Arthur (2014). This may be why Adeleke and Olorunsola (2010) stated "it is one thing to make users aware of the e-resources available in the library, whereas it is another to train them on how to access such electronic resources. It is the only way that academic libraries can help students learn and work in the digital environment". However, in comparison to the above databases containing Journal articles, e-book databases such as AccessMedicine, Clinicalkey, Science Direct and McGraw-Hill were found more known and used by the students. However, all these databases were found more used by the students of medicine than Dental students. The reason is obvious as these were more suited to medical students. The lack of e-book databases useful for dental students is very much evident from the study.

\section{Locations of Accessing Databases}

When asked about the preferred locations of accessing e-resources, the majority of respondents on an average indicated to access from home 76 (49.3\%), followed by library computer lab 73 (47.4\%) and through personal laptop or mobile using campus wife 65 (42.2\%). The results in table 6 confirm that library database access through Ezeproxy from off campus is very much utilized by the students. They prefer to access the e-resources in their leisure from home. However, a huge number of students also indicated to use the e-resources from the library computer lab and other locations of the institution using campus wifi which is also very satisfying and shows the availability of computer and communication infrastructure. Although, data analysis reveals the lack of computer facility in the college lab for students. They are mostly found using library computer lab and their own personal laptop and mobile for accessing e-resources. 
Table 6: Place of Access to Databases

\begin{tabular}{|l|c|c|c|c|c|c|}
\hline \multirow{2}{*}{ Locations of Access } & \multicolumn{4}{|c|}{ Colleges } & \multicolumn{2}{c|}{ Total } \\
\cline { 2 - 7 } & \multicolumn{2}{|c|}{ Medicine } & \multicolumn{2}{|c|}{ Dentistry } & \multicolumn{2}{c|}{} \\
\cline { 2 - 7 } & Freq & \% & Freq & $\%$ & Freq & $\%$ \\
\hline College Lab & 10 & 09.0 & 22 & 51.2 & 32 & 20.8 \\
\hline Campus Wifi (Using own Laptop, Mobile) & 37 & 33.3 & 28 & 65.1 & 65 & 42.2 \\
\hline Library Computer lab & 66 & 59.4 & 07 & 16.3 & 73 & 47.4 \\
\hline Home & 42 & 37.8 & 34 & 79.0 & 76 & 49.3 \\
\hline Other Locations & 08 & 07.2 & 03 & 06.9 & 11 & 07.1 \\
\hline
\end{tabular}

However, in the case of individual colleges, the data analysis found significant differences when comparing the percentages of access locations. Among $47.4 \%$ students found accessing e-resources through the library computer lab, merely $16.3 \%$ are from Dentistry college. It is probably because the location of the library is in the premises of Medical college, the Dental students are having difficulty during class hours to access and use the library computer lab. However, the result shows that dental college has better computer lab facilities (51.2\%) as compared to Medical college (9\%) and students are mostly found using it to access the e-resources. In addition, Dental students were found more satisfied with campus wifi facility (65.1\%) than their counterpart (33.3\%). This finding is also contradictory to that of Chirra and Madhusudhan (2009) where $86 \%$ of their respondents accessed from Departmental Computer Labs and only 36\% accessed from university libraries.

\section{Impact of Usage of E-Databases}

Having indicated their satisfaction with the databases, respondents were asked whether the use of databases has any impact on their academic performance? As shown in table 7, the impact of usage on respondents varied. The majority of respondents indicated little impact 72 (46.7\%), while 37 (24\%) claimed great impact. However, a considerable number of respondents indicated to have no impact 30 (19.5\%), while 15 (9.7\%) did not answer. Among those who felt no impact or did not answer, the majority of them (58.1\%) were from Dental college. The data analysis clearly indicates dissatisfaction from the part of Dental students over the impact of database usage. However, the reasons for the overall impact could not be fully ascertained and therefore can be pursued in future investigations.

Table 7: Distribution of Impact of Usage

\begin{tabular}{|l|c|c|c|c|c|c|}
\hline \multirow{2}{*}{ Impact of Usage } & \multicolumn{4}{|c|}{ Colleges } & \multicolumn{2}{c|}{ Total } \\
\cline { 2 - 7 } & \multicolumn{2}{|c|}{ Medicine } & \multicolumn{2}{|c|}{ Dentistry } & \multicolumn{2}{c|}{} \\
\cline { 2 - 7 } & Freq & \% & Freq & $\%$ & Freq & $\%$ \\
\hline No Impact & 11 & 09.9 & 19 & 44.1 & 30 & 19.5 \\
\hline Great Impact & 32 & 28.8 & 05 & 11.6 & 37 & 24.0 \\
\hline Little Impact & 59 & 53.1 & 13 & 30.2 & 72 & 46.7 \\
\hline Not Responded & 09 & 08.1 & 06 & 13.9 & 15 & 09.7 \\
\hline
\end{tabular}


Some of the students interviewed suggested that librarians and faculty should collaborate to enhance the effects of information literacy programs. This is similar to the findings of Barnard and Nash (2005) who stated that the implementation of an integrated curriculum promises advanced information skills, access, and use of available evidence to support clinical decision-making and a formation for lifelong learning.

\section{Favorite Databases}

The students were asked, among the databases they mentioned to have been used, which one is the most favorite database and why? A total of 154 respondents answered these two questions (Table 8). On the average, the following were the most favorite databases mentioned; ClinicalKey 50 (32.4\%), AccessMedicine 33 (21.4\%), Science Direct 21 (13.6\%), and Ovid $16(10.4 \%)$. The rest were below $10 \%$ of respondents. This finding is consistent with the databases they knew about and used especially for the first two in the ranking. The databases like Clinicalkey and AccessMedicine seemed to be more favorable to students of Medical college than the those of Dental college. The data analysis reveals the lack of any favorite databases maintained by the students of Dental college.

Table 8: Distribution of Favorite Databases by Respondents

\begin{tabular}{|l|c|c|c|c|c|c|}
\hline \multirow{2}{*}{ Databases } & \multicolumn{4}{|c|}{ Colleges } & \multicolumn{2}{c|}{ Total } \\
\cline { 2 - 7 } & \multicolumn{2}{|c|}{ Medicine } & \multicolumn{2}{c|}{ Dentistry } & \multicolumn{2}{c|}{} \\
\cline { 2 - 7 } & Freq & $\%$ & Freq & $\%$ & Freq & $\%$ \\
\hline PubMed & 03 & 02.7 & 04 & 09.3 & 07 & 04.5 \\
\hline Medline Plus & 00 & 00.0 & 00 & 00.0 & 00 & 00.0 \\
\hline Ovid & 11 & 09.9 & 05 & 04.5 & 16 & 10.4 \\
\hline SCOPUS & 00 & 00.0 & 00 & 00.0 & 00 & 00.0 \\
\hline ClinicalKey & 39 & 35.1 & 11 & 25.6 & 50 & 32.4 \\
\hline Science Direct & 14 & 12.6 & 07 & 16.3 & 21 & 13.6 \\
\hline BMJ & 00 & 00.0 & 00 & 00.0 & 00 & 00.0 \\
\hline AccesMedicine & 28 & 25.2 & 05 & 04.5 & 33 & 21.4 \\
\hline DynaMed & 00 & 00.0 & 00 & 00.0 & 00 & 00.0 \\
\hline Wiley & 08 & 07.2 & 03 & 07.0 & 11 & 07.1 \\
\hline Springer & 03 & 02.7 & 02 & 04.6 & 05 & 03.2 \\
\hline ProQuest & 02 & 01.8 & 01 & 02.3 & 03 & 01.9 \\
\hline EBSCO & 00 & 00.0 & 00 & 00.0 & 00 & 00.0 \\
\hline McGraw-Hill & 01 & 00.9 & 01 & 02.3 & 02 & 01.3 \\
\hline Anatomy.Tv & 02 & 01.8 & 03 & 07.0 & 05 & 03.2 \\
\hline Not any & 00 & 00.0 & 01 & 02.3 & 01 & 00.6 \\
\hline
\end{tabular}


The findings once again emphasize the most popular databases as Clinicalkey, AccessMedicine and Science Direct which are very much relevant and a prime source of E-books for the medical fraternity. For Dental students, E-books database of Qassim University was the only additional database mentioned together with the popular ones. The databases like ProQuest, EBSCO, PubMed, BMJ and Scopus, containing E-Journals were found less favorite. This once again shows the lack of research involvement from the part of students of both colleges. These databases need to be promoted through research guides, information literacy training classes and faculty-librarian collaboration.

Among the total 154 respondents, 109 responded to questions on why specific databases were chosen as favorites. In all, nine reasons were given for selecting databases as favorites and this is presented in Figure 1.

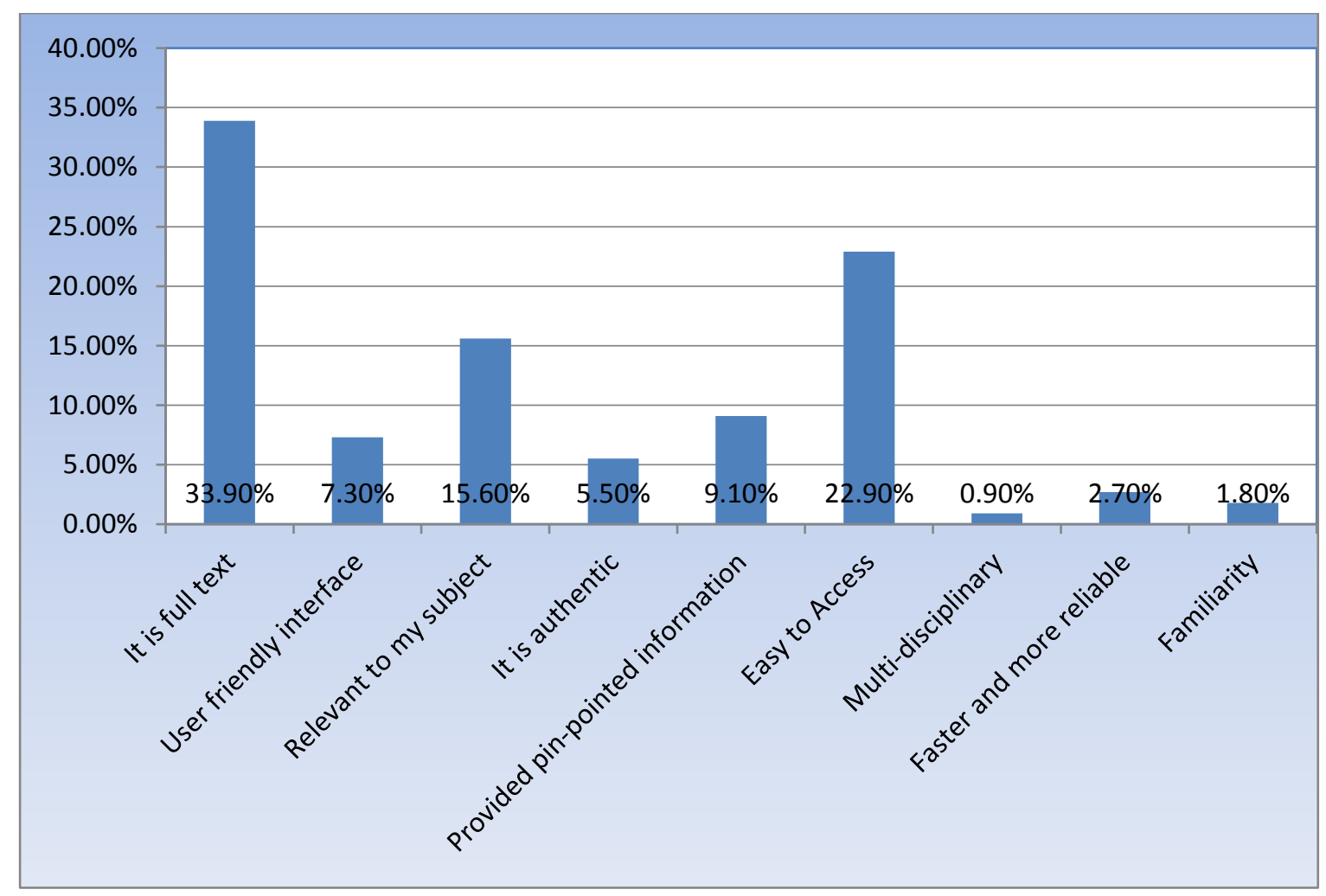

Figure. 1: Reasons for choice of databases

The most cited reason was 'It is full-text' 37 (33.9\%), followed by ease in the use of databases 25 (22.9\%) and relevance of the databases in their subject areas 17 (15.6\%). The rest of the reasons were cited by less than $10 \%$ of the respondents. This finding indicates that students value full-text and easy access above other reasons. This finding concurred with Hong Sinh and Thi Hong Nhung (2012) declaration that students liked easy to use things and quick to get results. Similarly, Cothran 
(2011) also found 3.86 mean on 1-5 scale for Google Scholar because it provides full-text and makes information easy to access.

\section{Factors affecting Use of E-Resources}

From table 9, it was observed that on an average, there is a general consensus by the respondents that factors like lack of skills needed to use online resources (61\%), accessing e-resources from out of campus (through Ezeproxy) (60.4\%), lack of time (46.7\%), Slow or limited access to Internet facility within the college premises (46.1\%), and ineffective user education program (40.3\%) are responsible for the ineffective use of e-resources.

The results clearly indicate that the students in the Faculty of Medical Sciences at Al-Jouf University lack the necessary information literacy skills needed to meet their academic and research requirements. This finding is in agreement with Lwehabura (2008) and Somi and De Jager (2005) who noted undergraduate students needed the necessary skills to fully utilize e-resources. It also conforms with Arora (2003) who recommended that medical and dental students need formal training in accessing the medical databases. It is the responsibility of medical librarians and faculty to educate students how to use information resources effectively. They need to intensify their efforts through proper user education programs to create awareness of scholarly online resources. Researchers like Baro, Endouware, and Ubogu (2011), Dulle and Lwehabura (2004) also highlighted the importance of integrating information literacy programs into existing courses.

Table 9: Different Factors affecting Use of E-Resources

\begin{tabular}{|l|c|c|c|c|c|c|}
\hline \multirow{2}{*}{ Factors } & \multicolumn{4}{|c|}{ Colleges } & \multicolumn{3}{c|}{ Total } \\
\cline { 2 - 6 } & \multicolumn{2}{|c|}{ Medicine } & \multicolumn{2}{|c|}{ Dentistry } & \multicolumn{2}{c|}{} \\
\cline { 2 - 6 } & Freq & $\%$ & Freq & $\%$ & Freq & $\%$ \\
\hline Lack of Skills & 57 & 51.3 & 37 & 86.0 & 94 & 61.0 \\
\hline Ineffective User Education Program & 27 & 24.3 & 35 & 81.4 & 62 & 40.3 \\
\hline Lack of time & 44 & 39.6 & 28 & 65.1 & 72 & 46.7 \\
\hline Internet Access Issues & 53 & 47.7 & 18 & 41.9 & 71 & 46.1 \\
\hline Technical problems with external server (Databases) & 18 & 16.2 & 08 & 18.6 & 26 & 16.9 \\
\hline Off Campus Access Issues(Ezeproxy/Internal Server) & 65 & 58.6 & 28 & 65.1 & 93 & 60.4 \\
\hline Lack of relevant Information/resources & 18 & 16.2 & 33 & 76.7 & 51 & 33.1 \\
\hline
\end{tabular}

Several studies have concluded that Internet is one of the most important source of information. Today, the internet is being used for medical education in various ways, including teaching, diagnosis, and conducting medical examinations (Mansor 2002, Virtanen and Nieminen 2002). But in spite of the popularity of the Internet, people may resist using it due to the slow response rate (DeLone and McLean 1992). Search results are successful only if the students get relevant, useful, 
specific and accurate information on time that could help them solve problems.It is evident from data analysis and interviews taken from the students that their information gathering efforts often suffered due to low or no internet access and server breakdowns especially in the case of off campus access.

One major problem students face in the process of searching for information and utilizing the resources is lack of time. Most of the students interviewed complained that they don't have enough leisure period to use the library and its resources. This finding is in accordance with the conclusion of Verhey (1999) who found lack of time to be a significant factor in searching and using e-resources for half of his nursing students. Some of the other problems that the students mentioned during interviews were, large mass of irrelevant information, lack of computer terminals, difficulties in navigating through electronic information and so on.

The findings on the differences between students of Medical and Dental Colleges on the issue of various factors affecting use of e-resources revealed that a large percentage of Dental students complained lack of relevant information resources 33 (76.7\%), searching skills 37 (86\%) and ineffective user education program 35 (81.4\%) than their counterpart. The differences could be due to low awareness level because of the ineffective user education program, library location, and less interest on the part of the students because of the availability of less number of electronic resources specifically devoted to dental specialty.

\section{CONCLUSION AND RECOMMENDATIONS}

Due to the need of medical professionals for high quality, authoritative, relevant, accurate and timely information, students studying in healthcare institutions need to know the various eresources and the best suitable way to track and access them in order to support their learning and evidence-based medical practice. Also on a personal level, they need to acquire research skills and develop clinical knowledge by learning how to perform effective literature searches from the universe of knowledge and then analyzing, appraising, applying and evaluating the information as the basis for clinical decisions. The present study has tried to compare the awareness and usability of medical students of two different colleges at Al Jouf University in using the subscribed electronic resources.

The study found that the awareness and utilization level of students related to available e-databases varied significantly especially when comparing individual colleges and databases. The overall knowledge and use of e-databases by medical students was much higher than the dental students and those who were aware of the existence of e-resources found using e-books' databases more 
than those containing journal publications and EBM.This shows that the students are more concerned to their courses of study than the clinical and research work. The overall low response from Dental students and lack of e-resources useful to them, are very much evident from the study. The study also found that those dissatisfied with the subscribed e-resources tend to use general search engines and databases of other university in order to meet their information needs.

The paper concludes that the undergraduate students in the FMS at Al-Jouf University lack the necessary information literacy skills needed to meet their academic and research requirements. In order to obtain some value for money that the university spent onto subscribe these databases, the paper suggests that the medical librarians and faculty should collaborate in promoting and making the students aware of these important resources. They need to intensify their efforts through proper information literacy programs to educate students how to use them effectively. In addition, it is suggested to implement an integrated curriculum promises advanced information skills, access, and use of available evidence to support clinical decision-making and a formation for lifelong learning.

There is a scope for future research that should concentrate on the investigation of: a) information seeking behavior of faculty, especially comparative studies of the disciplines, b) training needs analysis of medical students and faculty, c) evidence based resources in Saudi medical libraries, and d) investigating the impact of culture on the use of e-resources. It is anticipated that the results outlined in this paper, together with the recommendations, will be useful for those in decisionmaking roles and provide some insights for the people responsible for the selection of e-resources and application of IT at the university. It is further hoped that this paper will assist administrators of the university libraries in developing a more complete understanding of the electronic information needs of students and the barriers that may inhibit their optimal use.

\section{REFERENCES}

Adams, Judith A, and Sharon C Bonk. 1995. "Electronic information technologies and resources: use by university faculty and faculty preferences for related library services." College \& Research Libraries 56 (2):119-131.

Adeleke, AA, and R Olorunsola. 201" .0Training in the use of e-resources in academic libraries: one university's approach." Library Hi Tech News 27 (6/7):16-19.

Arora, R. 2003. "Computer and information technology skills of first year medical and dental students at CMC Ludhiana." Health Administrator 17 (1):54-58.

Asemi, Asefeh, and Nosrat Riyahiniya. 2007. "Awareness and use of digital resources in the libraries of Isfahan University of Medical Sciences, Iran." The Electronic Library 25 (3):316-327.

Atakan, Cemal, Dogan Atilgan, Özlem Bayram, and Sacit Arslantekin. 2008. "An evaluation of the second survey on electronic databases usage at Ankara University Digital Library." The Electronic Library 26 (2):249-259. 
Barnard, Alan, and Robyn Nash. 2005. "Information literacy: developing lifelong skills through nursing education." Journal of Nursing Education 44 (11):505.

Baro, Emmanuel E, Benake-ebide C Endouware, and Janet O Ubogu. 2011. "Awareness and use of online information resources by medical students at Delta State University in Nigeria." Library Hi Tech News 28 (10):11-17.

Chirra, Rekha, and Margam Madhusudhan. 2009. "Use of electronic journals by doctoral research scholars of Goa University, India." Library Hi Tech News 26 (10):12-15.

Coombs, Steven. 2005. "The Psychology of user-friendliness: The use of information technology as a reflective learning medium".

Cothran, Tanya. 2011. "Google Scholar acceptance and use among graduate students: A quantitative study." Library \& Information Science Research 33 (4):293-301.

Dadzie ,Perpetua S. 2005. "Electronic resources: access and usage at Ashesi University College." Campus-Wide Information Systems 22 (5):290-297.

Dee, Cheryl, and Ellen E Stanley. 2005. "Information-seeking behavior of nursing students and clinical nurses: implications for health sciences librarians*." Journal of the Medical Library Association 93 (2):213.

DeLone, William H, and Ephraim R McLean. 1992. "Information systems success: The quest for the dependent variable." Information systems research 3 (1):60-9.5

Dudley, Joseph M. 2013. "Facilitating undergraduate use of subscription research databases." TCC Proceedings. Retrieved from: etec. hawaii. edu/proceedings/2011/Dudley. pdf on 5th December.

Dukić, Darko. 2013. "Online databases as research support and the role of librarians in their promotion: The case of Croatia." Library Collections, Acquisitions, and Technical Services 37 (1-2):56-65.

Dulle, FW, and MJF Lwehabura. 2004. "User information literacy: Challenges facing university libraries towards effective implementation." Proceedings of the 6th Standing Conference of African National and University Libraries.

Ercegovac, Zorana. 2009. "What engineering sophomores know and would like to know about engineering information sources and access." Issues in Science \& Technology Librarianship 57.

Eskola, Eeva-Liisa. 2005. "Information literacy of medical students studying in the problem-based and traditional curriculum".

Gruppen, Larry D. 1990. "Physician information seeking: improving relevance through research." Bulletin of the Medical Library Association 78 (2):165.

Haines, Laura L. 2010. "Information-seeking behavior of basic science researchers: implications for library services**." Journal of the Medical Library Association 98 (1):73.

He, Daqing, Dan Wu, Zhen Yue, Anna Fu, and Kim Thien Vo. 2012. "Undergraduate students' interaction with online information resources in their academic tasks: a comparative study." Aslib Proceedings.

Hong Sinh, Nguyen, and Hoang Thi Hong Nhung. 2012. "Users' searching behaviour in using online databases at Vietnam National University-Ho Chi Minh City." Library Management 33 (8/9):458-468.

Kai-Wah Chu, Samuel, and Nancy Law. 2005. "Development of information search expertise: research students' knowledge of databases ".Online information review 29 (6):621-642.

Kwadzo, Gladys. 2015. "Awareness And Usage Of Electronic Databases By Geography And Resource Development Information Studies Graduate Students In The University Of Ghana." Library Philosophy and Practice:0_1.

Kwafoa, Paulina Nana Yaa, Imoro Osman, and Paulina Afful-Arthur. 2014. "Assessment of the use of electronic resources among administrators and faculty in the University of Cape Coast." Library Philosophy and Practice:0_1. 
Lwehabura, MJF. 2008. "Skills and training needs for use of electronic information resources (EIRs) among students in four Tanzanian Universities." University of Dar Es Salaam Library Journal 10 (1-2.)

Majid, Shaheen, and Yushiana Mansor. 1996. "Usage and promotion of CD-ROM services in Malaysian academic libraries." Computers in Libraries 16 (9):51-54.

Manda, Paul A. 2005. "Electronic resource usage in academic and research institutions in Tanzania." Information Development 21 (4):269-282.

Mansor, I. 2002. "Computer Skills among medical students: A survey at King Abdul Aziz University, Jeddah." Journal of Ayub Medical College 14 (3.)

Mbabu, Loyd Gitari, Albert Bertram, and Ken Varnum. 2013. "Patterns of undergraduates' use of scholarly databases in a large research university." The Journal of Academic Librarianship 39 (2):189-193.

Moberg, Thomas F, and Michael E Whitcomb. 1999. "Educational technology to facilitate medical students' learning: background paper 2 of the medical school objectives project." Academic Medicine 74 (10):1.50-146

Ndinoshiho, Joseph Megameno. 2010. "The use of electronic information services by undergraduate nursing students at the University of Namibia's Northern Campus: A descriptive study." Information Development 26 (1):57-65.

Nemati Anaraki, Leila, and Fahimeh Babalhavaeji. 2013. "Investigating the awareness and ability of medical students in using electronic resources of the integrated digital library portal of Iran: A comparative study." The Electronic Library 31 (1):70-83.

Nisha, Faizul, and Naushad Ali. 2012. "Awareness and use of e-journals by IIT Delhi and Delhi University library users." Collection Building 32 (2):57-64.

Okello-Obura, Constant. 2010. "Assessment of the problems LIS postgraduate students face in accessing e-resources in Makerere University, Uganda." Collection Building 29 (3):98-105.

Roberts, Jacqueline M. 1995. "Faculty knowledge about library services at the University of the West Indies." New Library World 96 (2):14-22.

Somi, Ntombizodwa G, and Karin De Jager. 2005. "The role of academic libraries in the enhancement of information literacy: a study of Fort Hare Library." South African Journal of Libraries \& Information Science 71 (3.)

Swain, Dillip K. 2010. "Students' keenness on use of e-resources." The Electronic Library 28 (4):580591.

Talja, Sanna, and Hanni Maula. 2003. "Reasons for the use and non-use of electronic journals and databases: A domain analytic study in four scholarly disciplines." Journal of documentation 59 (6):673-691.

Verhey, Marilyn P. 1999. "Information literacy in an undergraduate nursing curriculum: development, implementation, and evaluation." Journal of Nursing Education 38 (6):252259.

Virtanen, Jorma I, and Pentti Nieminen. 2002. "Information and communication technology among undergraduate dental students in Finland." European journal of dental education 6 (4):147152.

Wu, Ming-der, and Shih-chuan Chen. 2012. "How graduate students perceive, use, and manage electronic resources." Aslib Proceedings.

Zabed Ahmed, SM. 2013. "Use of electronic resources by the faculty members in diverse public universities in Bangladesh." The Electronic Library 31 (3):290-312.

Zondi, Lindiwe Elda. 1992. "Library-use skills and information-seeking patterns of first-year students at the University of Zululand." South African journal of library and information science 60:204-204. 